\title{
Analyzing the Use of Medicinal Herbs During the First Wave and Second Wave of COVID-19
}

\author{
Tanvi Singh $^{1} \cdot$ Arti Nigam $^{1} \cdot$ Rachna Kapila $^{1}$
}

Received: 11 July 2021/Revised: 11 July 2021 / Accepted: 23 September 2021 / Published online: 12 January 2022

(C) The National Academy of Sciences, India 2022

\begin{abstract}
India has confronted the COVID-19 pandemic in 2020 , in the form of first wave and again in first half of 2021 in the form of second wave. To combat the persistent transmission of the coronavirus, Indian Government has started the vaccination in the country since January 2021. The immunity conferred by the vaccine can be more effective with sound immune health. In India, medicinal herbs are preferred dietary habits to enhance the immunity intrinsically. A web-based survey of herbal medicinal plants was carried out to identify the consumption trend of the medicinal herbs as an effective immune booster to reduce the spread of COVID-19. The selected herbs are ingredients of regular Indian cuisine and practiced under Ayurveda. The present study revealed that people are aware of selected medicinal herbs and consumed intentionally to boost their immunity. This type of study can be helpful in retaining the local people's knowledge on traditional medicine practices which has been vanishing.
\end{abstract}

Keywords COVID-19 · Pandemic $\cdot$ Herbs ·

Immune health $\cdot$ Ayurveda

Significance Statement: This study can be helpful in retaining the local people's knowledge on traditional medicine practices. The results can also be exploited in researches in the field of biochemistry, pharmacology and phytochemistry and also can improve the immune system.

Rachna Kapila

rachnakapila.ihe@gmail.com

1 Institute of Home Economics, University of Delhi, New Delhi 110016, India

\section{Introduction}

Beginning in 2019, December, the primary instances of pneumonic conditions brought about by a new coronavirus were accounted in Wuhan, China [1]. From that point, there was a quick expansion in the quantity of recognized and affirmed cases because the infection was fit for humanto-human transmission. On February 11, 2020, World Health Organization (WHO) formally named this novel infection as coronavirus disease-2019 (COVID-19) [2]. Entire world has confronted this pandemic circumstance in 2020, in the form of first wave and specifically India, again in first half of 2021 in the form of second wave. High contagiousness and high infectivity of COVID-19 assisted it to spread all around the world and the human expense kept on mounting $[3,4]$. The disease has spread in around 218 nations and territories, resulting in around 39.9 lakh deaths.

The wonderful endeavors of entire clinical and pharmaceutical fraternity have successfully been able to produce vaccines against novel COVID disease. As of late, the Government of India has dispatched two effective vaccines Covishield and Covaxin to counter COVID-19. Health experts and professional, nonetheless, additionally exhort the importance of innate immune system for efficiency of vaccine. Agreeing the distressing health effects of COVID19 , numerous nations executed a widespread and severe non-drug intervention to moderate the rate of contamination. Herbal preparations have consistently been focused on, among the few potential competitors, for further development of resistance [5, 6]. Use of herbs to improve the resistance stands more pertinent in Indian subcontinent where Ayurveda holds the foundations of clinical framework. Ayurvedic preparations have served as a cure for many deadly and contagious diseases since time and 
memorial. As recommended by Ministry of AYUSH, commonly used herbs have been selected for the study. These herbs are as follows: Garlic (Allium sativum), Dalchini (Cinnamomum zeylanicun), Lemon (Citrus limon), Coriander (Coriandrum sativum), Jeera (Cuminum cyminum), Turmeric (Curcuma longa), Mentha (Mentha spp.), Black pepper (Piper nigrum), Clove (Syzygium aromaticum), Ajwain (Trachyspermum ammi), Methi (Trigonella foenum-graecum), Ginger (Zingiber officinale), Neem (Azadirachta indica), Amla (Emblica officinalis), Tulsi (Osmium sanctum), Mumijo or Shilajit, Kutki (Picrorhiza kurroa), Giloy (Tinospora cordifolia), Ashwagandha (Withania somnifera). The herbs selected for the survey are popular culinary herbs which are used in regular Indian cuisine and/or are practiced under Indian Ayurveda medicine [7]. These medicinal herbs are most widely used as antioxidants, antiseptic, anti-carcinogenic, antibacterial, antiviral, antimalarial, anti-common flu, indigestion, edema, cough, immune boosters and immune-modulatory agents. Amla, Giloy, Neem, Kutki, Ashwagandha, Shilajit and Mentha have been known for their role as immunemodulatory, anti-inflammatory and antiviral agents [8-13].

Considering the efficiency and use of herbs by common people in their day to day life, a study was conducted through a general web-based survey among Indian adults regarding the awareness of herbs as important immune booster to fight against COVID-19 and to reduce its spread.

\section{Material and Methods}

The survey was conducted by Department of Biology in collaboration with Department of Microbiology, Institute of Home Economics, University of Delhi, India. The mode of survey was online, based on Google form. This was to obtain data on utilization of herbs as immunity booster during COVID-19 pandemic, first wave as well as second wave. The survey was conducted in the month of October 2020 after the first wave and in April 2021, during the second wave of this pandemic. A total of 300 individuals participated in the survey. Majority of the participants were of the age group 18-30 years $(70 \%)$ while the rest were adults of age group 30-60 years (30\%).

The questionnaire was prepared in the form of Google form and confirmed by the experts from Department of Epidemiology \& Clinical Research, Institute of Liver and Biliary Sciences, New Delhi, India. In total, 19 herbs were selected which are commonly known and used by individuals, according to the information from expert.

The questionnaire consisted of questions based on utilization of herbs and each question had name of herb in Hindi and English for ease of identification. The survey forms were disseminated through private and institutional networks (email and WhatsApp). The results were randomly divided into three groups of 100 respondents each, for statistically significant analysis. The participants and questions were kept same during both the sets of survey. Participants personal information including name were anonymized to maintain confidentiality. Such anonymous nature of web-based survey does not require approval from Ethical Committee.

Statistical analyses-The data set was subjected for analysis using a paired sample $t$ test through Statistical Package for Social Sciences version 26 (SPSS).

\section{Results and Discussion}

To fight the tenacious spread of the Coronavirus among human population, scientists have come up with vaccines and Indian Government has started the process of vaccination since January 2021. However, the question that still remains unanswered and is in the mind of the people is that how long the immunity conferred by the vaccine will last? Secondly, for the proper effectiveness of vaccines, a good immune system is essential. Thus, besides vaccine, herbal immunity booster will also play an integral role in combating the COVID-19 pandemic.

The study received 300 responses which were divided into three separate groups of 100 response each, for statistically significant analysis. On the basis of medicinal efficiency of herbs, after reviewing literature, in total 19 herbs were selected for study $[7,14,15]$. On the basis of survey conducted during first as well as second wave of COVID-19, use frequency of herbs was calculated. Our results show that during the first wave of COVID-19, the most used herbs were Ginger (Z. officinale), Amla ( $E$. officinalis), Garlic (A. sativum) with use frequency more than $80 \%$, followed by Clove (S. aromaticum) and Lemon (C. limon) with use frequency between 70 and $80 \%$, then, Neem (A. indica), Shilajit, Black pepper ( $P$. nigrum), Giloy (T. cordifolia), Turmeric (C. longa), Holy basil (Osmium sanctum), Mentha (Mentha spp.), Dalchini (C. zeylanicun) having use frequency between 60 and $70 \%$, Jeera $(C$. cyminum), Coriander (C. sativum), Ashwagandha ( $W$. somnifera) and Ajwain (T. ammi) having use frequency between 50 and $60 \%$ and Methi (T. foenum-graecum), Kutki (Picrorhiza kurroa) with use frequency between 40 and $50 \%$.

The survey during second wave of COVID-19 showed Amla, Dalchini and Garlic to be the most used herbs with use frequency more than $80 \%$, followed by Neem, Turmeric, Black pepper, Clove, Giloy and Ginger with use frequency between 70 and 80\%. Further, Ajwain, Shilajit, Lemon, Holy basil, Mentha and Ashwagandha had use frequency between 60 and $70 \%$, Jeera and Coriander 
having use frequency between 50 and $60 \%$ and Methi and Kutki being least used with use frequency between 40 and $50 \%$. Table 1 shows the most and least used herbs during both the waves of COVID-19.

Further, comparative analysis shows that out of 19 herbs, the use frequency of 11 herbs showed no significant increase or decrease $(p>0.05)$. Of the remaining 8 herbs, Neem, Dalchini, Ashwagandha, Turmeric, Black pepper and Giloy showed increase in used frequency $(p<0.05)$ during second wave as compared to first wave of COVID19 and the use of Lemon and Ginger was more during first wave $(p<0.05)$ (Fig. 1).

Several studies have confirmed the effectiveness of these herbal preparations against COVID-19 [16-22]. The increase in use frequency of herbs in the second wave can be attributed to the spreading of traditional knowledge during first wave along with continuous efforts to educate young minds by the Ministry of AYUSH, about the importance of Ayurveda on health benefits as well as persuading people to drink herbal immune booster called colloquially kadha during this pandemic time [23]. The results show that young population is well aware about the herb-induced immunity or the significance of herbs in boosting immunity. This study corroborates with the study conducted by El Alami et al. [24]. However, the present study does not suggest that these medicinal plants are the

Table 1 Use of herbs during first wave and second wave of COVID19 pandemic

\begin{tabular}{lllll}
\hline First wave & & & Second wave & \\
\cline { 5 - 5 } Most used & Least used & & Most used & Least used \\
\hline Ginger & Methi & & Amla & Methi \\
Amla & Kutki & & Dalchini & Kutki \\
Garlic & & Garlic &
\end{tabular}

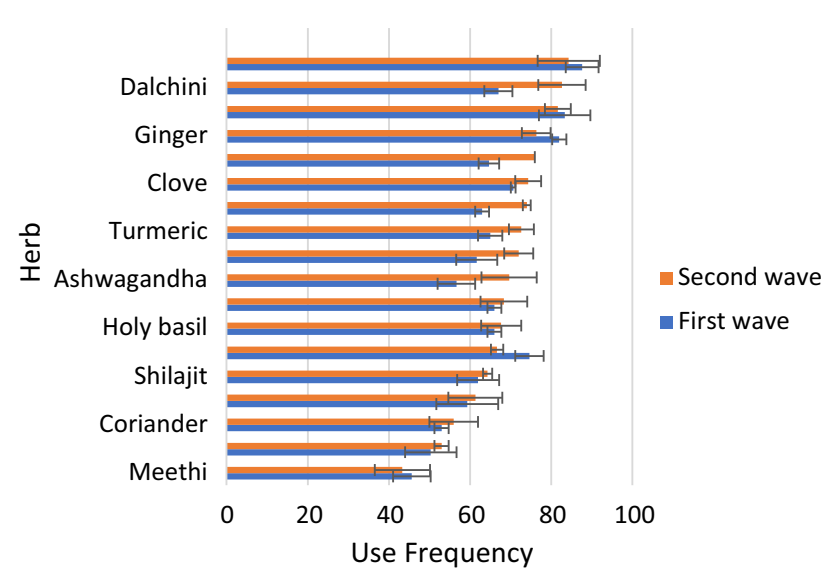

Fig. 1 Use frequency of the herbs used during the COVID-19 pandemic, first wave and second wave cure of COVID-19 but herbal preparations can improve the immune system that in turn can help us in combating the situation.

\section{Conclusion}

This study anticipated the awareness about use of herbs in regular Indian cuisine as immunity booster against COVID-19 due to the presence of bioactive ingredients. Herbs were taken purposely by the Indian adults to enhance their immunity during the COVID-19. This type of study can be helpful in retaining the local people's knowledge on traditional medicine practices which has been vanishing. The results can also be exploited in researches in the field of biochemistry, pharmacology and phytochemistry and also can improve the immune system.

Acknowledgements The authors are thankful to the participants of this survey.

\section{Declarations}

Conflict of interest The authors declare that they have no conflict of interest.

\section{References}

1. Shim E, Mizumoto K, Choi W, Chowell G (2020) Estimating the risk of COVID-19 death during the course of the outbreak in Korea, February-May 2020. J Clin Med 9(6):1641

2. WHO (World Health Organization) (2020) WHO coronavirus disease (COVID-19) dashboard. https://covid19.who.int/.Accessed 5 July 2021

3. Dowd JB, Andriano L, Brazel DM, Rotondi V, Block P, Ding X, Liu Y, Mills MC (2020) Demographic science aids in understanding the spread and fatality rates of COVID-19. PNAS 117(18):9696-9698

4. Fang Y, Nie Y, Penny M (2020) Transmission dynamics of the COVID-19 outbreak and effectiveness of government interventions: a data-driven analysis. J Med Virol 92(6):645-659

5. Gautam S, Gautam A, Chhetri S, Bhattarai U (2020) Immunity against COVID-19: potential role of ayush kwath. J Ayurveda Integr Med. https://doi.org/10.1016/j.jaim.2020.08.003

6. Lin LT, Hsu WC, Lin CC (2014) Antiviral natural products and herbal medicines. eJTCM 4(1):24-35

7. Park SY, Kim DS (2002) Discovery of natural products from Curcuma longa that protect cells from beta-amyloid insult: a drug discovery effort against Alzheimer's disease. J Nat Prod 65(9):1227-2123

8. Kumar V, Singh SB, Singh S (2020) COVID-19: environment concern and impact of Indian medicinal system. J Environ Chem Eng 8:104144

9. Chambial S, Dwivedi S, Shukla KK, John PJ, Sharma P (2013) Vitamin $\mathrm{C}$ in disease prevention and cure: an overview. Indian $\mathrm{J}$ Clin Biochem 28(4):314-328

10. Schepetkin IA, Khlebnikov AI, Ah SY, Woo SB, Jeong CS et al (2003) Characterization and biological activities of humic substances from mumie. J Agric Food Chem 51(18):5245-5254 
11. Schepetkin IA, Xie G, Jutila MA, Quinn MT (2009) Complement-fixing activity of fulvic acid from Shilajit and other natural sources. Phytother Res 23(3):373-384

12. Sharma P, Dwivedee BP, Bisht D, Dash AK, Kumar D (2019) The chemical constituents and diverse pharmacological importance of Tinospora cordifolia. Heliyon 5(9):e02437

13. Tiwari V, Darmani NA, Yue BY, Shukla D (2010) In vitro antiviral activity of neem (Azardirachta indica L.) bark extract against herpes simplex virus type-1 infection. Phytother Res 24(8):1132-1140

14. Nikhat S, Fazil M (2020) Overview of Covid-19; its prevention and management in the light of Unani medicine. Sci Total Environ 728:138859

15. Pundarikakshudu K, Kanaki NS (2019) Analysis and regulation of traditional Indian medicines (TIM). J AOAC Int 102:977-978

16. Harmukh N (2020) Medicinal plants and their uses in natural immunity improvement with special reference to covid-19. In: Desai N, Pawar U, Aparadh V, Patil M (eds) Research interventions and advancements in plant sciences, 1st edn. Bhumi Publishing, India, pp 169-174

17. Baildya N, Khan AA, Ghosh NN, Dutta T, Chattopadhyay AP (2021) Screening of potential drug from Azadirachta Indica (Neem) extracts for SARS-CoV-2: an insight from molecular docking and MD-simulation studies. J Mol Struct 1227:129390
18. Desai A, Desai C, Desai H, Mansuri A, Desai J (2020) Possible role of medicinal plants in COVID-19-a brief review. IJSRD 5(4):205-209

19. Kanyinda JNM (2020) Coronavirus (COVID-19): a protocol for prevention and treatment (Covalyse $\left.{ }^{\circledR}\right)$. Eur J Med Heal Sci 2:1-4

20. Khubber S, Hashemifesharaki R, Mohammadi M, Gharibzahedi SMT (2020) Garlic (Allium sativum L.): a potential unique therapeutic food rich in organosulfur and flavonoid compounds to fight with COVID-19. Nutr J 19(1):1-3

21. Rajagopal K, Byran G, Jupudi S, Vadivelan R (2020) Activity of phytochemical constituents of black pepper, ginger, and garlic against coronavirus (COVID-19): an in-silico approach. Int J Res Health Allied Sci 9(5):43-43

22. Tanveer $\mathrm{T}$ (2020) Immunity boosting measures during COVID19. JAHM 6(2):40-42

23. Khanna K, Kohli SK, Kaur R, Bhardwaj A, Bhardwaj V et al (2020) Herbal immune-boosters: substantial warriors of pandemic Covid-19 battle. Phytomedicine 85:153361

24. El Alami A, Fattah A, Chait A (2020) Medicinal plants used for the prevention purposes during the covid-19 pandemic in Morocco. JASAB 2(1):2-1

Publisher's Note Springer Nature remains neutral with regard to jurisdictional claims in published maps and institutional affiliations. 